\title{
STUDENT AWARD WINNERS
}

\section{The MRS Honors Ten Promising Scientists At The Annual Meeting}

Ten outstanding graduate students have been selected to receive the recognition and support of the Materials Research Society at this year's Annual Meeting. They represent the very finest candidates from among a larger pool of talented student scientists put forward by their professors and judged on the basis of their academic achievement, the quality of the research upon which they will report, and the promise of successful careers their ability and enthusiasm suggests.

The Chairperson of the Student Awards Committee, Kathleen C. Taylor of General Motors Research Laboratories, said in announcing the awards: "The quality of the candidates this year was exceptionally high. The research of the ten graduate students selected was, however, of such a caliber that it set them apart from their peers and made our task a little less difficult. Their-contributions to the symposia of the Society are important. It was felt they are well prepared to join their scientific colleagues as full participants."

Kathy, who initiated the student awards and has guided the selection process from the beginning, added: "The Awards were conceived in the spirit of encouraging promising scientists and engineers to devote themselves to the study of materials. Also, the Awards are a means of bringing very capable student scientists and engineers to the attention of their professional colleagues. As competition for the Awards increases each year, it is evident these goals are being met."

Student Award winners will present papers before seven of this year's symposia. They have received a travel grant to make their participation possible.
The winners, their affiliation, field of study, symposium and paper are:

MICHAEL J. AZIZ; Harvard University; Materials Science; Energy Beam-Solid Interactions and Transient Thermal Processing; "Crystal Growth and Solute Trapping."

LUC BAUFAY; University de l'Etat, Mons; Physics; Energy Beam-Solid Interactions and Transient Thermal Processing and Laser-Controlled Chemical Processing of Surfaces; "The Influence of Layer Structures on the Synthesis of AlSb by Laser Irradiation

\section{'Their Contributions To The Symposia of The Society Are Important'}

of $\mathrm{Al} / \mathrm{Sb}$ Thin Film Couples," with A. Pigeolet and R. Andrew, and "TimeResolved Optical Reflectivity and Transmission During Laser-Induced Oxidation of Cadmium Films," with M. Wautelet, A. Pigeolet and R. Andrew.

PHILIP JOHN BURNETT; University of Cambridge; Materials Science; Ion Implantation and Ion Beam Processing of Materials; "The Hardness of $\mathrm{MgO}$ by Ion Implantation," with T.F. Page.

CALVIN H. CARTER, JR.; North Carolina State University; Materials Engineering; Energy Beam-Solid Interactions and Transient Thermal Processing and Defect Properties and Processing of High-Technology Nonmetallic Materials; "The Occurrence of Defects in Silicon Carbide as a Function of Processing Mode and Applied Stress," with J. Bentley and R.F. Davis, and "Influence of Rapid Thermal Annealing on
Shallow $\mathrm{BF}_{2}$ Implantation Into PreAmorphized Silicon," with W. Maszara, D.K. Sadana, J. Liu, V. Ozgug, J. Wortman and G. Rozgonyi.

PHILIPPE M. FAUCHET; Stanford University; Applied Physics; Energy Beam-Solid Interactions and Transient Thermal Processing; "Two Color Picosecond Measurements on ElectronHole Plasmas Close to the Melting Phase Transition," with A.E. Siegman and E.L. Ginzton.

M. YASSER KHALIL; The Pennsylvania State University; Nuclear Engineering; Scientific Basis for Nuclear Waste Management; "Dissolution of Technetium from Nuclear Waste Forms," with W.R. White.

JERZY H. MAZUR; University of California, Berkeley; Materials Science; Electron Microscopy of Materials; "High Resolution TEM of Interfaces in Semiconductors," with J. Washburn.

KAREN JEANNE MORRISSEY; Cornell University; Materials Science; Defect Properties and Processing of High-Technology Nonmetallic Materials; "Special Grain Boundaries in $\mathrm{Al}_{2} \mathrm{O}_{3}$," with C.B. Carter.

TIMOTHY SANDS; University of California, Berkeley; Materials Science; Electron Microscopy of Materials; "High Resolution Study of the Relationship Between Misfit Accommodation and Growth of $C u_{2-x} S$ in CdS," with J. Washburn and G. Gronsky.

JOSEPH A. STROSCIO; Cornell University; Physics; Catalytic Reaction Mechanisms: The Role of Surface Structure and Composition; "Mechanisms for the Adsorption and Catalytic Reactions of Hydrogen and Ethylene on Ni(110)," with S.R. Bare and W. Ho. 